\title{
A Novel Multi Frequency Rectangular Microstrip Antenna with Dual T Shaped Slots for UWB Applications
}

\author{
D.RamyaKeertana ${ }^{1}$,M.V.S.D.N.N.Murthy ${ }^{2}$, B. Yeswanth $^{3}$,Ch.Rajasekhar ${ }^{4}$ \\ D.Naresh Kumar \\ 1,2,3,4,5: Department of Electronics \& Communications Engineering Lendi Institute of Engineering and \\ Technolog. Affiliated to JNTU kakinada
}

\begin{abstract}
This paper presents the design and simulation of rectangular microstrip antenna with Dual T-shaped slots for wireless communicaions with frequency standards $3.1 \mathrm{GHz}$ to $10.6 \mathrm{GHz}$ specified by IEEE 802.15.3a.The shape will provide the bandwidth which is required in various application like remote sensing, mobile radio, etc. The antenna design is an improvement from previous research with single $T$ slot and it is simulated. Microstrip line edge feeding technique is used in the design analysis. The performance of the designed antenna was analyzed in terms of bandwidth, gain, return loss, VSWR, and radiation pattern. Substrate used here is DUROID which has a dielectric loss tangent of 0.0009. The results show that the antenna is able to operate at $4.84 \mathrm{GHz}$ and $6.81 \mathrm{GHz}$ frequency band with operating frequency at $5 \mathrm{GHz}$.
\end{abstract}

Keywords:multi frequency, microstrip,

\section{Introduction}

Microstrip antennas consist of a very thin metallic strip (patch) on a grounded substrate found extensive applications in different fields due to their attractive features. These antennas are low profile, low weight, low cost, compact and comfortable structure and easy to fabricate. These antennas have drawn attentions of scientific community over the past decades. These antennas can be easily put on any surfaces and may be easily coupled with MIC Components. However their low gain values and bandwidth constraints limit their usage in Commercial Applications.

Microstrip antennas are characterized by a larger number of physical parameters than conventional microwave antennas. They can be designed to have many geometrical shapes and dimensions but rectangular and circular Microstrip resonant patches have been used extensively in many application Nowadays scientific community is deeply involved in improving their performance so that these may replace other antenna structures in modern communication systems.In the present communication we have presented a rectangular patch micro strip antenna with dual $\mathrm{T}$ shaped slot using microstrip edge feeding technique. The simulation analysis of this antenna is carried out on Ansoft High Frequency structured Simulation software (HFSS).

\subsection{Microstrip Edge Feed:}

In this type of feed technique, a conducting strip is connected directly to the edge of the micro strip patch. The conducting strip is smaller in width as compared to the patch and this kind of feed arrangement has the advantage that the feed can be etched on the same substrate to provide a planar structure.

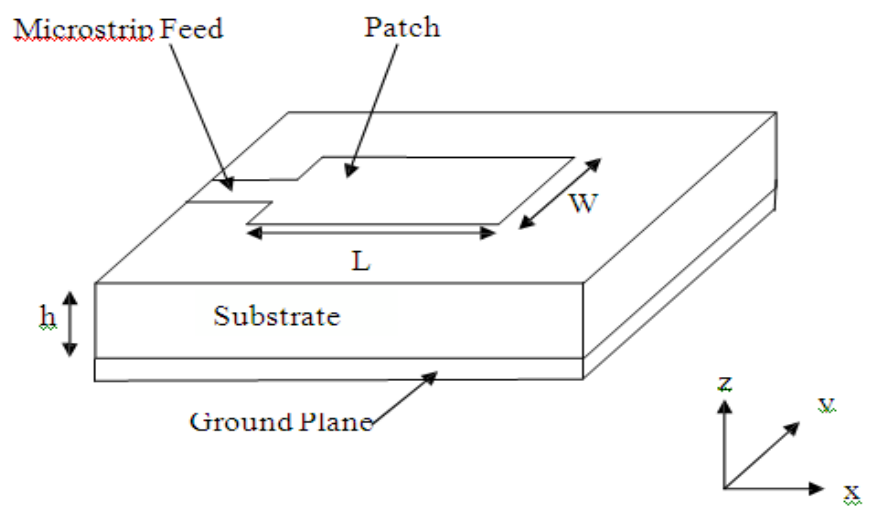

Fig 1 :Microstrip edge feed 


\subsection{Antenna Design:}

\section{Antenna Design Specifications}

The antenna showed in Fig 2 consists of a rectangular patch on Duroid substrate with two T-shaped slots in order to have the drastic variations in the pattern resonance frequencies. The dimensions of the proposed antenna are summarized by accepting these conditions $\mathrm{W}>\mathrm{L}, \mathrm{W}<2 \mathrm{~L}$

\section{1: Calculation of Width (W)}

For an efficient radiators, practical width that leads to good radiation efficiencies.

$\mathrm{W}=\frac{1}{2 \mathrm{f}_{\mathrm{r}} \sqrt{\mu_{0} \varepsilon_{0}}} \sqrt{\frac{2}{\varepsilon_{\mathrm{r}}+1}}=\frac{\mathrm{C}}{2 \mathrm{f}_{\mathrm{r}}} \sqrt{\frac{2}{\varepsilon_{\mathrm{r}}+1}}$

$\mathrm{C}=$ Velocity of light

$\varepsilon_{r}=$ dielectric constant of substrate

\section{2: Calculation of the Effective Dielectric Constant ( $\left.\varepsilon_{e f f}\right)$}

The effective dielectric constant is

$\varepsilon_{\mathrm{eff}}=\frac{\varepsilon_{\mathrm{r}}+1}{2}+\frac{\varepsilon_{\mathrm{r}}-1}{2}\left(\frac{1}{\sqrt{1+\frac{12 \mathrm{~h}}{\mathrm{w}}}}\right)$

\section{3: Calculation of Effective Length}

The Effective length is

Leff $=\frac{C}{2 f_{r} \sqrt{\varepsilon_{e f f}}}$

\section{4: Calculation of actual Length of Patch ( $L$ )}

The actual length of radiating patch is obtained by

$L=L_{e f f}-2 \Delta L$

III. Analysis of Antenna Geometry

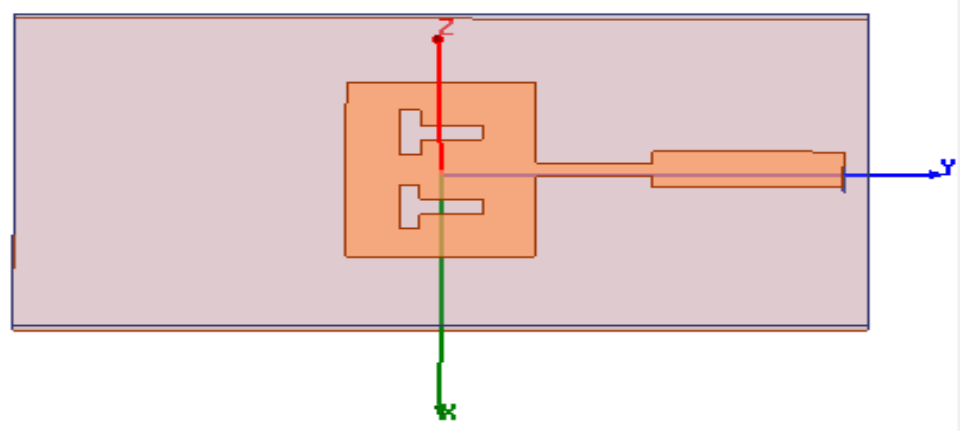

Fig 2: Model of Antenna 
3.1 Patch dimensions:

\begin{tabular}{|l|l|}
\hline $\mathrm{X}(\mathrm{cm})$ & 2.34 \\
\hline $\mathrm{Y}(\mathrm{cm})$ & 1.82 \\
\hline
\end{tabular}

\subsection{Substrate parameters}

\begin{tabular}{|l|c|}
\hline Relative permittivity & 2.2 \\
\hline Relative permeability & 1 \\
\hline Dielectric loss tangent & 0.0009 \\
\hline Height (mil) & 70 \\
\hline $\mathrm{X}(\mathrm{cm})$ & 4.2 \\
\hline $\mathrm{Y}(\mathrm{cm})$ & 8.2 \\
\hline
\end{tabular}

\subsection{Making "T" slot on patch}
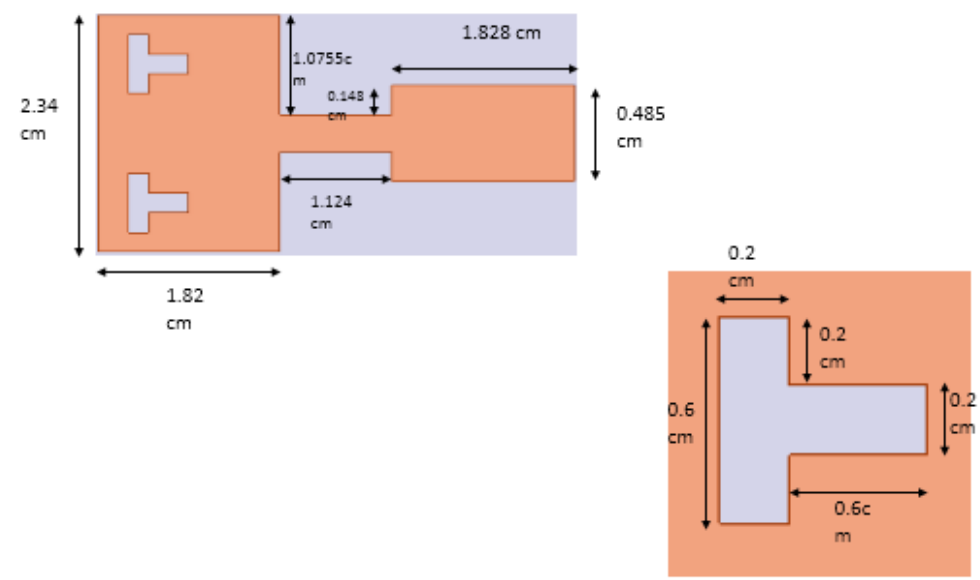

Fig 3:Dimensions

When $\mathrm{T}$ shaped slots as shown in Fig 3, introduced on the patch geometry, the antenna now resonates at different frequencies.

\section{Results and Discussions}

The simulated results for this modified antenna are optimized by varying position, length and width of $\mathrm{T}$ shaped slot.

Fig 4 shows the return loss for the designed antenna. This indicates that the antenna operates at $4.8 \mathrm{GHz}$ and $6.8 \mathrm{GHz}$ frequencies.

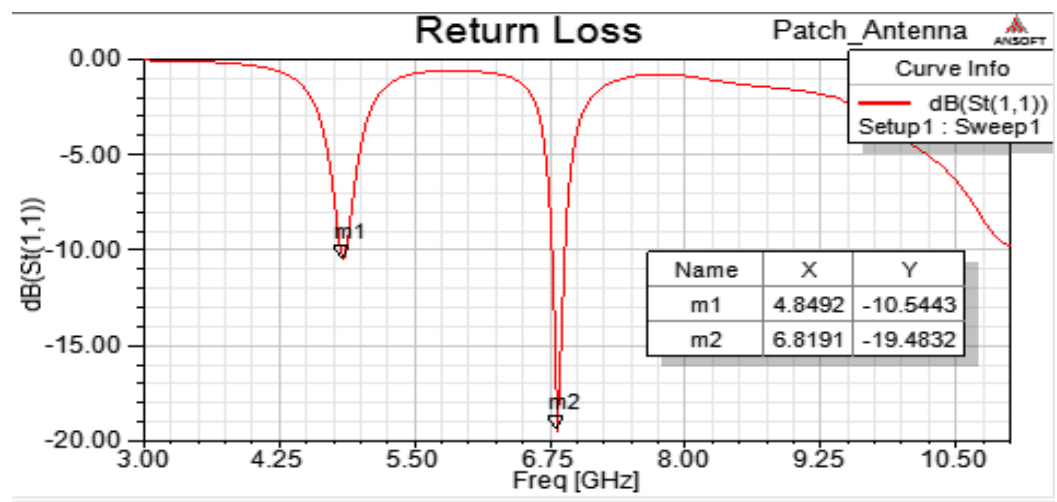

Fig 4: Return loss 


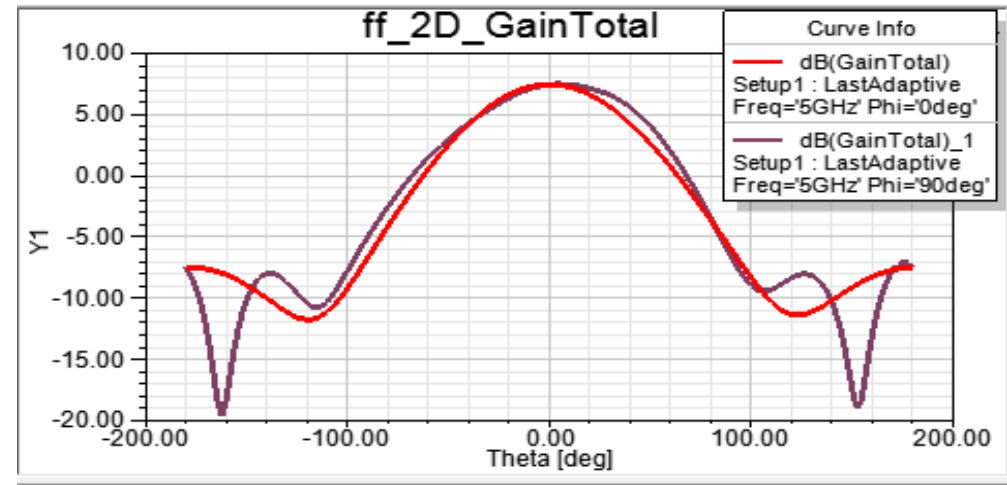

Fig 5: 2d gain plot

\section{Radiation Pattern:}

Fig 6 shows the simulation results of the radiation patterns for the proposed patch on DUROID substrate along $E$ and $H$-planes.

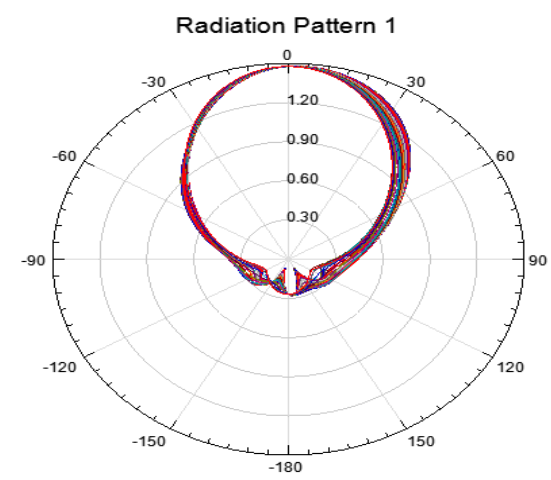

Fig 6: Radiation pattern

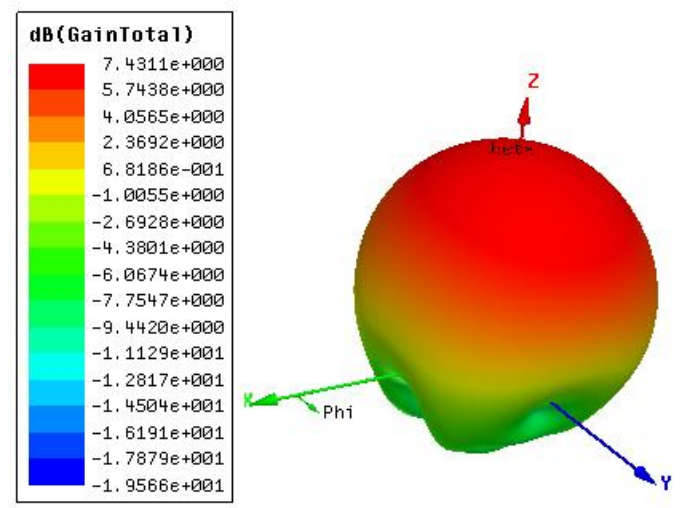

Fig 7: 3d gain 


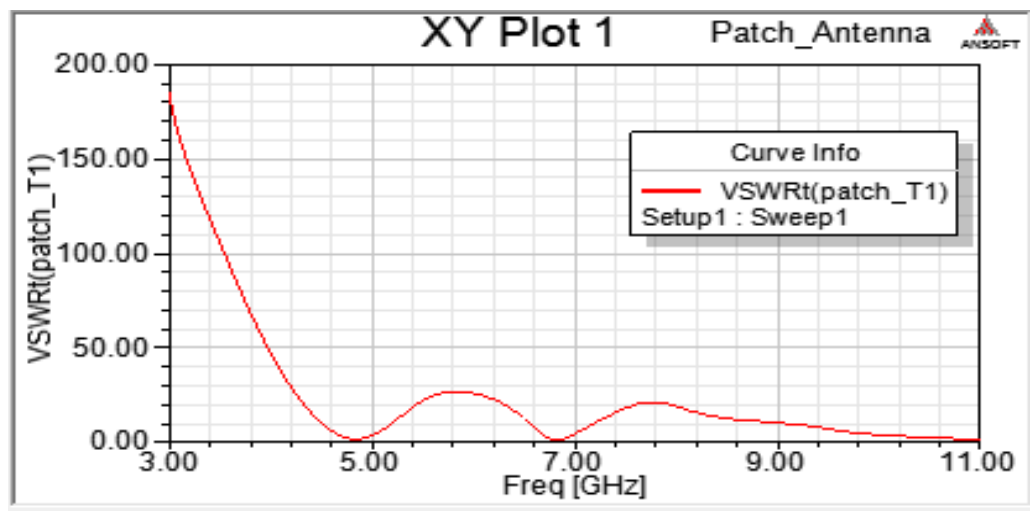

Fig 8 : VSWR plot

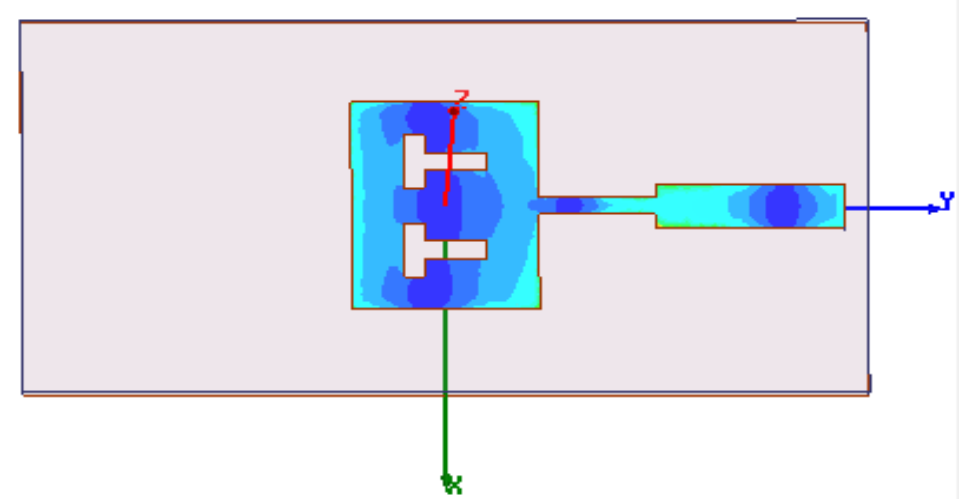

Fig 9: Electric field distribution pattern

\section{Conclusion}

The paper presents A Multi Frequency Rectangular microstrip Antenna with dual T Shaped Slots for Ultra wide band (UWB) applications with frequency ranging from $3.1 \mathrm{GHz}$ to $10.6 \mathrm{GHz}$ which is specified by IEEE standards 802.15.3a. The analysis is carried out by considering duroid substrate material using HFSS.The results show that the antenna is able to operate at $4.84 \mathrm{GHz}$ and $6.81 \mathrm{GHz}$ frequencies with operating frequency at 5 GHz.

\section{References}

[1] Antenna Theory Analysis and Design, Restricted not for sale in North America Edition, Constantine A. Balanis, Wiley, 2005

[2] R. Garg, P. Bhartia, I. J. Bahl and A Ittipiboon, Microstrip antenna design handbook, ArtechHouse:New York, 2001.

[3] Inc. NY, USA. Richard C. Johnson, Henry Jasik, "Antenna Engineering Handbook" Second Edition 1984, pp 7-1 to 7- 14, McGraw Hill,

[4] K. L. Wong, Compact and Broadband Microstrip Antennas, John Wiley \& Sons. 2003

[5] J. Huang (1983) The finite ground plane effect on the Microstrip Antenna radiation pattern, IEEE Trans. Antennas Propagate, vol. AP-31, no. 7, pp. 649-653

[6] Nader Engheta, Richard W. Ziolkowski, “Metamaterial Physics \& Engineering Explorations”, Wiley-IEEE Press, June 2006. 